\title{
Q1 Produção de biomassa de Brachiaria ruziziensis adubada com farinha de ossos calcinada sob tratamentos ácidos
}

\author{
João Batista Dias Damaceno ${ }^{1}$ \\ Elvino Ferreira ${ }^{2}$ \\ Danielle Monteiro de Oliveira ${ }^{3}$ \\ Rodrigo de Souza Guimarães ${ }^{4}$ \\ Romildo Torres da Gama 5 \\ Felipe de Jesus Padilha ${ }^{6}$
}

\section{Resumo}

Com as reservas de fósforo diminuindo gradativamente, o interesse em desenvolver alternativas para suprir a demanda de fertilizantes na agricultura vem sendo cada dia maior. Com isso, atentou-se para os resíduos orgânicos advindos do abate de animais, como ossos bovinos, que são fontes de fósforo $(\mathrm{P})$ e cálcio $(\mathrm{Ca})$ e podem ser destinados à agricultura. $\mathrm{O}$ único impasse na sua utilização é sua baixa solubilidade e disponibilidade de nutrientes às plantas. Assim, objetivou-se avaliar os efeitos produtivos da forrageira Brachiaria ruziziensis quando submetida à adubação com farinha de ossos calcinada (FOC) sob tratamentos ácidos (oxálico a $10 \%$, acético a $10 \%$ e clorídrico a 1 e 0,5\%, respectivamente). Nas avaliações foram consideradas as seguintes variáveis: matéria fresca da parte aérea (MFPA), matéria seca da parte aérea (MSPA) e potencial hidrogeniônico $(\mathrm{pH})$. Como padrão utilizou-se do superfosfato simples (SFS) para comparação. A acidificação da FOC proporcionou ganhos significativos de MFPA e MSPA na presença $\mathrm{HCl}_{1 \%}$ e o Acé ${ }_{10 \%}$ como extratores de $\mathrm{P}$ em relação à testemunha e à FOC sem utilização dos ácidos. A utilização de todos os ácidos na FOC proporcionou aumentos significativos no $\mathrm{pH}$ do solo.

Palavras-chave: Fósforo. Fontes alternativas. Resíduos pecuários. Forrageiras.

\section{Introdução}

De acordo com levantamentos do Instituto Brasileiro de Geografia e Estatística - IBGE (2010), - Brasil possui um rebanho bovino de aproximadamente 210 milhões de cabeças e sua maioria é criada a pasto de forma extensiva. Entre as pastagens brasileiras utilizadas para este fim, estima-se que entre 60 e $80 \%$ das pastagens plantadas no Brasil estejam sofrendo processos de degradação (FERRAZ; FELÍCIO, 2010). Segundo a Organização das Nações Unidas para Alimentação e Agricultura - FAO (2009), as principais causas de degradação de pastagens são o manejo inadequado, a capacidade de recuperação do pasto, as altas taxas de lotação e o pisoteio por animais. Além dessas

1 Fundação Universidade Federal do Amazonas (UFAM), doutorando em Agronomia (Produção Vegetal). Av. André Araújo, 2936, Aleixo, CEP 69060-001. Manaus, Amazonas, Brasil. joaodiasrm@gmail.com.

2 Fundação Universidade Federal de Rondônia (UNIR), professor titular do Departamento de Agronomia. elvinoferreira@yahoo.com.br.

3 Universidade Estadual Júlio de Mesquita Filho (UNESP), doutora em Ciências Florestais. dmoliveira.am@gmail.com.

4 Instituto Nacional de Pesquisas da Amazônia (INPA), mestre em Agronomia (Agricultura no Trópico Úmido).rsg_fca@yahoo.com.br.

5 Instituto Nacional de Pesquisas da Amazônia (INPA), mestrando em Agronomia (Agricultura no Trópico Úmido). romildo.ufpa@hotmail.com.

6 Instituto Nacional de Pesquisas da Amazônia (INPA), mestre em Agronomia (Agricultura no Trópico Úmido). felipejpadilha@gmail.com. 
causas, Dias-Filho (2011) inclui como fator importante de contribuição a ausência ou ineficiência das adubações corretivas ou de manutenção.

Na região amazônica, é estimado que cerca de 50 \% das pastagens plantadas sofram algum processo de degradação ou já estejam degradadas pelo seu uso explorativo (SALMAN, 2007; COSTA et al., 2009; DIAS-FILHO, 2011). Entre os estados da Amazônia, o estado de Rondônia configura-se como um dos principais no setor de bovinocultura e pastagens. No entanto, é estimado que aproximadamente 5 milhões de hectares, onde havia florestas nativas, estão ocupados por pastagens cultivadas. Deste total, cerca de $40 \%$ apresentam diferentes estágios de degradação e esses processos resultam na abertura de novas áreas (COSTA et al., 2004; DIAS-FILHO, 2011). Nos estudos de Dias-Filho (2011) sobre as principais causas de degradação de pastagens em Rondônia, observou-se que a ausência de adubação, principalmente a fosfatada, aparece como causa principal desse processo.

A principal deficiência observada nos solos tropicais é a do fósforo $(P)$, que apresenta níveis muito baixos, sendo necessário que se promova a manutenção desse nutriente por meio de fontes externas de P. Sugere-se que a principal limitação na produtividade das pastagens seja a limitação de $\mathrm{P}$ e, em áreas degradadas, as forrageiras respondem bem à adubação com esse nutriente (DIAS-FILHO, 1998, 2014). No entanto, para realizar a manutenção de $P$ nesses solos, as principais opções de fontes utilizadas que suprem essa demanda pelas pastagens são o superfosfato simples (SFS) e o superfosfato triplo (SFT) que são fertilizantes solúveis.

O grande impasse em utilizar de forma sistemática esses fertilizantes é a capacidade de produção das reservas de fosfato provenientes de rochas, pois há um indicativo de que as reservas comerciais desses fosfatos irão se esgotar entre 60 e 150 anos, resultando também em uma elevação gradual dos preços esperada para as próximas décadas (OELKERS; VALSAMI, 2008; LAPIDO-LOUREIRO et al., 2009). Devido a esse fato, torna-se necessário o desenvolvimento e estudo de fontes alternativas de $\mathrm{P}$ que supram essa demanda por fertilizantes com a mesma eficiência e garantia desse nutriente (PORTO et al., 2012). Estudos realizados por Costa et al. (2009) evidenciaram que resíduos sólidos processados, como a farinha de ossos bovinos, podem suprir a demanda das plantas por nutrientes essenciais, como o P, devido a suas composições químicas. Gomes, Malavolta e Alcarde (2002) mencionam que o uso da farinha de ossos tem potencial como adubo fosfatado, tal como o superfosfato simples e o superfosfato triplo.

No Brasil, segundo o IBGE (2015), apenas no $2^{\circ}$ trimestre de 2015 foram abatidas 7,63 miIhões de cabeças de bovinos, gerando 1,84 milhões de toneladas de carcaças. Esses ossos bovinos apresentam grande concentração de $\mathrm{P}$, sendo relatados quase o dobro em sua composição quando comparados ao superfosfato simples; além disso, com o processo de queima desses ossos, evidencia-se a calcinação que, após a moagem, torna-se a farinha de ossos calcinada (FOC), com concentração elevada de óxido de cálcio.

O ponto negativo em se utilizar a FOC na agricultura é o fato de essa ser uma fonte de $\mathrm{P}$ de baixa solubilidade em água, sendo praticamente indisponível às plantas quando aplicada, o que demanda de acidificação para solubilização do fósforo presente, assim como ocorre com os fosfatos de rocha. Os pontos positivos na sua utilização são as quantidades dessa matéria-prima no Brasil, o aproveitamento de resíduos, a produção de forma manual e a sustentabilidade do sistema, uma vez que FOC pode retornar como fertilizante de pastagens (KOZEN; ALVARENGA, 2010; FERRO; CUNHA; FERREIRA, 2013). O objetivo deste trabalho foi analisar a eficiência da FOC como fertilizante quando submetida a distintos tratamentos ácidos aplicada em Brachiaria ruziziensis. 


\section{Material e métodos}

Este trabalho foi realizado na área da Fazenda Experimental da Universidade Federal de Rondônia, município de Rolim de Moura nas coordenadas $11^{\circ} 34^{\prime}$ 58,60" S e 6146'22,30" W a 277 m acima do nível do mar. 0 clima segundo classificação de Köppen é do Tipo Aw, com estação seca bem definida, temperatura mínima de $24^{\circ} \mathrm{C}$, máxima de $32{ }^{\circ} \mathrm{C}$ e média de $28{ }^{\circ} \mathrm{C}$, com precipitação anual de $2.250 \mathrm{~mm}$ e com umidade relativa do ar elevada, oscilando em torno de $85 \%$ (PEEL; FINLAYSON; MCMAHON, 2007). O experimento foi conduzido no período de outubro de 2014 a fevereiro de 2015, totalizando cinco meses de avaliação. Os tratamentos utilizados estão descritos abaixo (Tabela 1).

O estudo foi conduzido em um delineamento inteiramente casualizado (DIC), com sete tratamentos e três repetições. Como fontes fosfatadas, foi utilizada a farinha de ossos calcinada (FOC), submetidas a diferentes concentrações de extratores e o superfosfato simples (SFS), visto que este último foi utilizado como padrão para os outros tratamentos (Tabela 1). Para cada fonte foram utilizados $100 \mathrm{~kg} \mathrm{ha}^{-1}$ de $\mathrm{P}_{2} \mathrm{O}_{5}$, respeitando-se as concentrações de $\mathrm{P}_{2} \mathrm{O}_{5}$ cada uma. Adicionalmente, adotou-se uma testemunha geral (sem adubação) e uma testemunha para FOC (sem uso de extratores). As duas fontes de $\mathrm{P}$ estudadas foram trituradas e passadas em peneira de $2 \mathrm{~mm}$ para que fossem avaliadas em iguais condições.

Tabela 1. Tratamentos experimentais utilizando Farinha de Ossos Calcinada

\begin{tabular}{|c|c|c|}
\hline Trat. & Descrição & Símbolo \\
\hline 1 & Nitrogênio (Ureia) + Potássio (Cloreto de Potássio) + Fósforo (Superfosfato Simples) & SFS \\
\hline 2 & $\begin{array}{l}\text { Nitrogênio (Ureia) + Potássio (Cloreto de Potássio) + Fósforo (Farinha de Ossos } \\
\text { Calcinada tratada com Ácido Oxálico a } 10 \text { \%) }\end{array}$ & Oxá ${ }_{10 \%}$ \\
\hline 3 & $\begin{array}{l}\text { Nitrogênio (Ureia) + Potássio (Cloreto de Potássio) + Fósforo (Farinha de Ossos } \\
\text { Calcinada tratada com Ácido Acético a } 10 \text { \%) }\end{array}$ & Acé ${ }_{10 \%}$ \\
\hline 4 & $\begin{array}{l}\text { Nitrogênio (Ureia) + Potássio (Cloreto de Potássio) + Fósforo (Farinha de Ossos } \\
\text { Calcinada tratada com Ácido Clorídrico a } 1 \text { \%) }\end{array}$ & $\mathrm{HCl}_{1 \%}$ \\
\hline 5 & $\begin{array}{l}\text { Nitrogênio (Ureia) + Potássio (Cloreto de Potássio) + Fósforo (Farinha de Ossos } \\
\text { Calcinada tratada com Ácido Clorídrico a 0,5\%) }\end{array}$ & $\mathrm{HCl}_{0,5 \%}$ \\
\hline 6 & $\begin{array}{l}\text { Nitrogênio (Ureia) + Potássio (Cloreto de Potássio) + Fósforo (Farinha de Ossos } \\
\text { Calcinada sem tratamento ácido) }\end{array}$ & FOC \\
\hline 7 & Testemunha Sem adubação & Test. \\
\hline
\end{tabular}

Fonte: Elaborada pelos autores (2018).

O solo utilizado foi coletado e peneirado na própria área experimental e foi classificado como Latossolo Vermelho Amarelo Eutrófico (EMPRESA BRASILEIRA DE PESQUISA AGROPECUÁRIA EMBRAPA, 2006) apresentando as seguintes características: $\mathrm{pH}$ em água $=5,4$; Matéria Orgânica

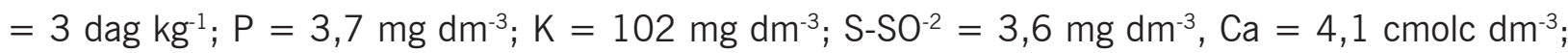
Mg: 1,4 cmolc dm${ }^{-3} ; \mathrm{Fe}=88 \mathrm{mg} \mathrm{dm}^{-3} ; \mathrm{Cu}=1,8 \mathrm{mg} \mathrm{dm}^{-3} ; \mathrm{Zn}=1,5 \mathrm{mg} \mathrm{dm}^{-3} ; \mathrm{Mn}=25 \mathrm{mg} \mathrm{dm}^{-3} ; \mathrm{B}$ $=0,14 \mathrm{mg} \mathrm{dm}^{-3}, \mathrm{H}+\mathrm{Al}=4,8 \mathrm{cmolc} \mathrm{dm}^{-3} ; \mathrm{Al}=0,12 \mathrm{cmolc} \mathrm{dm}^{-3} ; \mathrm{SB}=5,7 \mathrm{cmolc} \mathrm{dm}^{-3} ; \mathrm{T}=10,5$ cmolc dm ${ }^{-3} ; \mathrm{V}=54 \% ; \mathrm{m}=2 \%$; Areia $=530 \mathrm{~g} \mathrm{~kg}^{-1}$; Silte $=83 \mathrm{~g} \mathrm{~kg}^{-1}$; Argila $=381 \mathrm{~g} \mathrm{~kg}^{-1} \mathrm{para}^{\mathrm{a}}$ camada de $0-20 \mathrm{~cm}$. 
Adicionalmente aos tratamentos com adição de fontes fosfatadas, realizou-se a adubação complementar conforme as recomendações de Costa (2004). Foram aplicados para correção e manutenção dos níveis de $\mathrm{N}$ e $\mathrm{K}$ do solo, respectivamente: $100 \mathrm{~kg} \mathrm{ha}^{-1}$ de $\mathrm{N}$ e $60 \mathrm{~kg} \mathrm{ha}^{-1}$ de $\mathrm{K}_{2} \mathrm{O}$. Não foi realizada calagem com o objetivo de verificar a influência da FOC sobre o pH. As fontes, concentrações e parcelamento da adubação estão descritas abaixo (Tabela 2).

Tabela 2. Fontes e concentrações dos fertilizantes aplicados no transplantio e em cobertura

\begin{tabular}{lcccc}
\hline Fontes & Concentrações & Plantio $\left(\mathrm{g}^{-1} /\right.$ Vaso) & \multicolumn{2}{c}{ Cobertura (g-1/Naso) } \\
\hline & & & 60 DAT $^{1}$ & 90 DAT \\
\cline { 3 - 4 } Ureia & $45 \% \mathrm{~N}$ & 0,430 & 0,430 & 0,430 \\
Cloreto de Potássio & $60 \% \mathrm{~K}_{2} \mathrm{O}$ & 0,226 & - & - \\
Superfosfato Simples & $18 \% \mathrm{P}_{2} \mathrm{O}_{5}$ & 1,261 & - & - \\
Farinha de Ossos Calcinada & $35,7 \% \mathrm{P}_{2} \mathrm{O}_{5}$ & 0,635 & - & - \\
\hline
\end{tabular}

${ }^{1}$ Dias Após Transplantio.

Fonte: Elaborada pelos autores (2018).

O plantio da $B$. ruziziensis foi realizado por meio de mudas coletadas e padronizadas na área experimental com altura média de $12 \mathrm{~cm}$ e massa média de 4,52 g, totalizando três mudas por recipiente, dispostas uniformemente. As unidades experimentais foram constituídas por vasos plásticos, com capacidade de 3,9 kg de solo peneirado. Os vasos foram dispostos a céu aberto e sob condições naturais, as quais se aproximam ao máximo das condições reais para o período. As regas diárias foram feitas até que as chuvas se estabilizassem (a partir de dezembro) e não houvesse mais necessidade, mantendo-se a mesma quantidade de água/ recipiente (300 ml/vaso/dia), utilizando regador manual. A retirada de plantas daninhas provenientes do banco de sementes do solo coletado foi feita de forma manual e conforme a ocorrência dentro de cada recipiente no início da implantação.

A FOC utilizada no experimento foi produzida de forma manual, em que foram coletados ossos bovinos de firma idônea, sendo realizada a queima desses para eliminação dos componentes orgânicos e maceração para diminuição das partículas. No processo de obtenção da FOC, os ossos bovinos foram alocados em churrasqueira de alvenaria e acomodados em grades de tela moeda, utilizando carvão para a queima. 0 material foi queimado por aproximadamente 8 horas, apresentando coloração acinzentada após o resfriamento. Logo após, os ossos foram triturados com uso de gral e pistilo e peneirados em malha de $2 \mathrm{~mm}$ para padronização. Amostras de FOC foram enviadas para análises dos teores de nutrientes. Foi constatada a presença de 35,7 \% de $\mathrm{P}_{2} \mathrm{O}_{5}, 43,76 \%$ de $\mathrm{CaO}$.

No sentido de aumentar a solubilidade do fosfato, foram utilizados os ácidos oxálico, acético e clorídrico (PAs) como extratores de P para a farinha de ossos. Para os ácidos oxálicos e acético, foi utilizada uma diluição de $10 \mathrm{ml}$ dos produtos para cada $100 \mathrm{ml}$ de água destilada. Para o ácido clorídrico (PA) foi utilizada uma diluição de 1 e 0,5 ml do ácido para cada $100 \mathrm{ml}$ de água destilada. As soluções foram aplicadas para $100 \mathrm{~g}$ de farinha de ossos. Após as aplicações, a farinha foi homogeneizada e levada à estufa de circulação de ar forçado à temperatura de $65^{\circ} \mathrm{C}$ até atingir massa constante.

Para efeito de avaliação dos resultados foram analisadas as seguintes variáveis: massa fresca da parte aérea (MFPA); massa seca da parte aérea (MSPA) e potencial hidrogeniônico ( $\mathrm{pH})$. A MFPA foi obtida por meio da realização dos cortes da forrageira e posterior pesagem, utilizando balança digital de precisão. A MSPA foi obtida da mesma forma, porém com posterior secagem em estufa 
de circulação de ar forçada com temperatura de $65^{\circ} \mathrm{C}$, durante 72 horas até a obtenção de massa constante.

Foram consideradas três épocas de avaliação: 60, 90 e 120 dias após o transplantio das mudas. Foram realizadas análises estatísticas de cada época de avaliação e, com as médias de cada período avaliado, obteve-se uma média geral das produções de MFPA e MSPA, realizando-se a análise geral. Para a avaliação do pH, ao final do experimento (120 dias), foi adotado o método de avaliação de $\mathrm{pH}$ em água na relação 1:2,5 (EMBRAPA, 1997). Os dados foram submetidos à análise de variância e o contraste de médias pelo Teste de Tukey a $5 \%$ de probabilidade. Para auxiliar nas análises foi utilizado o programa Assistat 7.7 (SILVA; AZEVEDO, 2009).

\section{Resultados e discussão}

As plantas de $B$. ruziziensis se desenvolveram até 60 dias após o transplantio, possibilitando o primeiro corte da forrageira com $25 \mathrm{~cm}$ do solo. Obtiveram-se maiores incrementos de MFPA e MSPA quando foi aplicado o tratamento com $\mathrm{P}$ mais solúvel e prontamente disponível à forrageira. O SFS proporcionou acúmulo de MFPA e MSPA de 509,8 \% e 592,3 \%, respectivamente, em relação ao tratamento testemunha absoluta (Tabela 3).

Tabela 3. Produção de Matéria Fresca da Parte Aérea (MFPA) e Matéria Seca da Parte Aérea (MSPA) de $B$. ruziziensis $\left(\mathrm{g} \mathrm{kg}^{-1}\right)^{1}$ aos 60,90 e 120 dias após plantio.

\section{Dias Após Transplantio -DAP}

\begin{tabular}{|c|c|c|c|c|c|c|c|c|}
\hline \multirow[t]{2}{*}{ Trat. $^{2}$} & \multicolumn{2}{|c|}{60} & \multicolumn{2}{|c|}{90} & \multicolumn{2}{|c|}{120} & \multicolumn{2}{|c|}{ Média } \\
\hline & MFPA & MSPA & MFPA & MSPA & MFPA & MSPA & MFPA & MSPA \\
\hline SFS & $41,3 a^{3}$ & $10,2 \mathrm{a}$ & $24,9 \mathrm{a}$ & $6,5 \mathrm{a}$ & $27,0 \mathrm{a}$ & $6,4 \mathrm{a}$ & $31,1 \mathrm{a}$ & $7,7 \mathrm{a}$ \\
\hline Oxá ${ }_{10 \%}$ & $23,7 \mathrm{bc}$ & $5,5 \mathrm{bc}$ & $21,4 \mathrm{a}$ & $5,4 a b$ & $23,1 \mathrm{a}$ & 5,5 a & $22,7 \mathrm{abc}$ & $5,5 \mathrm{abc}$ \\
\hline Acé ${ }_{10 \%}$ & 26,9 b & $6,5 \mathrm{bc}$ & $20,1 a b$ & $5,0 a b c$ & $22,8 \mathrm{a}$ & 5,4 a & $23,3 a b$ & $5,6 a b$ \\
\hline $\mathrm{HCl}_{1 \%}$ & $28,7 \mathrm{~b}$ & $8,0 a b$ & $18,3 a b$ & $4,5 a b c$ & 23,4 a & $5,6 a$ & $23,5 a b$ & $6,0 a b$ \\
\hline $\mathrm{HCl}_{0,5 \%}$ & $16,3 \mathrm{~cd}$ & $3,8 \mathrm{~cd}$ & 12,6 bc & $3,2 \mathrm{bcd}$ & $14,0 \mathrm{~b}$ & $3,3 \mathrm{~b}$ & $14,3 \mathrm{bcd}$ & $3,4 \mathrm{bcd}$ \\
\hline FOC & 11,2 de & $2,3 \quad d$ & $12,2 \mathrm{bc}$ & $2,6 \mathrm{~cd}$ & $10,2 \mathrm{bc}$ & $2,4 \mathrm{bc}$ & $11,2 \mathrm{~cd}$ & $2,4 \mathrm{~cd}$ \\
\hline Test. & 6,0 e & $1,4 \quad \mathrm{~d}$ & $6,1 \quad c$ & $1,2 \quad \mathrm{~d}$ & $6,3 \quad c$ & $1.5 \mathrm{C}$ & $6,1 \quad \mathrm{~d}$ & $1,3 \quad \mathrm{~d}$ \\
\hline CV (\%) & 15.27 & 19.90 & 8.07 & 23.58 & 10.57 & 10.60 & 22.26 & 23.95 \\
\hline $\mathrm{F}$ & 37.4 & 25.2 & 14.0 & 10.7 & 50.6 & 50.4 & 12.5 & 12.2 \\
\hline $\mathrm{p}$ & $<0.001$ & $<.0001$ & $<.0001$ & $<.0001$ & $<0.001$ & $<0.001$ & $<.0001$ & $<.0001$ \\
\hline
\end{tabular}

${ }^{1}$ Recipiente plástico (3,9 kg). ${ }^{2}$ Tratamentos aplicados: Superfosfato Simples (SFS); FOC + Ácido oxálico a 10\% (Oxá ${ }_{10 \%}$ ); FOC + Ácido Acético a 10\% (Acé ${ }_{10 \%}$ ); FOC + Ácido Clorídrico a ${ }_{1 \%}\left(\mathrm{HCl}{ }_{1 \%}\right)$; FOC + Ácido Clorídrico $a_{0,5 \%}\left(\mathrm{HCl}_{0,5 \%}\right.$ ); Farinha de ossos calcinada ( $\mathrm{FO}$ C) e Testemunha (Test.). ${ }^{3}$ As médias seguidas pela mesma letra na coluna nấo diferem entre si pelo Teste de Tukey ao nível de $5 \%$ de probabilidade.

Fonte: Elaborada pelos autores (2018). 
Quando comparado o tratamento padrão (SFS) com o tratamento FOC, observaram-se ganhos de produção de MFPA e MPSA de 277,6 \% e 320,8 \%, respectivamente, evidenciando que a baixa solubilidade inicial da FOC (0,26 \%) (FERREIRA; BALBINO, 2014) prejudicou o desenvolvimento inicial da $B$. ruziziensis. A maior produção de MSPA pode estar ligada à alta disponibilidade de $\mathrm{P}$ pelo SFS, que oferece boas condições iniciais para a planta. Não foram observados sintomas pela deficiência de $\mathrm{P}$, como manchas arroxeadas nas folhas, sintomas citados na literatura em gramíneas (COELHO et al., 2002). Contudo, mesmo aplicando doses recomendadas de $\mathrm{N}$ e $\mathrm{K}$ para a forrageira, o tratamento apenas com FOC promoveu decrécimos na produção de MFPA e MSPA. Esse efeito confirma que a ausência ou a baixa disponibilidade de $P$ limita a produção vegetal (FAGERIA, 2008). $O$ efeito dos baixos níveis de $\mathrm{P}$ disponível pode também ter diminuído a absorção de nitrogênio na planta e é reportado na literatura, pois existe interação entre os elementos (LIRA et al., 1994).

Quando utilizado os extratores ácidos, ocorreram maiores produções de MFPA e MSPA na $B$. ruziziensis em relação ao tratamento sem extrator (FOC). Na média dos três cortes realizados foram obtidos incrementos significativos, com o tratamento $\mathrm{HCl}_{1 \%}\left(23,5 \mathrm{~g} \mathrm{~kg}^{-1}\right)$ e $\left(6,0 \mathrm{~g} \mathrm{~kg}^{-1}\right)$ e Acé ${ }_{10 \%}$ $\left(23,3 \mathrm{~g} \mathrm{~kg}^{-1}\right)$ e $\left(5,6 \mathrm{~g} \mathrm{~kg}^{-1}\right)$, respectivamente, para MFPA e MSPA. Tal comportamento é indicativo do potencial de uso da FOC acidificada para promoção da reciclagem de nutrientes a aproveitamento de resíduos para a agricultura familiar em locais onde o comércio de carnes ainda não conta com grande desenvolvimento e, por isso, os ossos são descartados de maneira não criteriosa no ambiente, provocando poluição e transtornos sanitários.

A relação de produção de MFPA e MSPA entre $\mathrm{HCl}{ }_{1 \%} /$ Test. $(3,85 ; 4,61)$ e entre Ace ${ }_{10 \%} /$ Test. $(3,81 ; 4,30)$ não está tão distante daquela gerada com o uso do SFS $(5,09 ; 5,92)$, havendo necessidade de ser estudado o uso da FOC como fonte de P com o uso de extratores ácidos em diferentes concentrações. O Ácido Clorídrico $(\mathrm{HCl})$ é um ácido forte que apresenta maior potencial para solubilização e consequente disponibilidade de $\mathrm{P}$ para ser absorvido pelas plantas quando empregado em baixas concentrações. Em termos práticos, para o aproveitamento desses resíduos, conta-se comercialmente com o ácido muriático ( $\mathrm{HCl}$ comercial) de custo menor aos reagentes PAs e ainda usado de forma diluída para obtenção de efeitos satisfatórios na solubilização de $\mathrm{P}$ em relação às diferentes exigências das forrageiras.

Na prática, esses extratores ácidos dissolvem predominantemente o $\mathrm{P}$ ligado ao Ca e quantidades menores de $\mathrm{P}$ ligado a Fe e Al, em função das características de solubilidade dos fosfatos (OLSEN; KHASAWNEH, 1980). O uso de reagentes comerciais contenta ácido sulfúrico para solubilização de $\mathrm{P}$ por poder deixar quantidade de enxofre na FOC, o que é interessante para solos com deficiência desse elemento. Quando aplicado o tratamento $\mathrm{HCl}_{1 \%}$, obtiveram-se resultados superiores para MFPA $(60,85 \%)$ e MSPA $(56,66 \%)$ do que o tratamento $\mathrm{HCl}$ 0,5\%, reforçando que concentrações em soluções com $\mathrm{HCl}$ menor que $1 \%$ promovem decréscimo na disponibilidade de $\mathrm{P}$ às forrageiras e posterior utilização na solução (Tabela 3).

Alcançaram-se bons resultados para os ácidos orgânicos, que são considerados ácidos fracos, o Ácido Acético $\left(\mathrm{CH}_{3} \mathrm{COOH}\right)$ e o Ácido Oxálico $\left(\mathrm{H}_{2} \mathrm{C}_{2} \mathrm{O}_{4}\right)$ a $10 \%$. Quando aplicado o Acé ${ }_{10 \%}$ e o Oxá ${ }_{10 \%}$ foram conquistados 51,93 \% e 57,14\%; 50,66 \% e 56,36 \%, respectivamente, em incrementos na MFPA e MSPA em relação à FOC. Por serem ácidos fracos, necessitam de concentrações mais elevadas quando comparados a ácidos fortes $(\mathrm{HCl})$. Cabe ressaltar que alguns ácidos, como o acetato, são produzidos pelas raízes das plantas, que por um lado inibem o crescimento radicular, mas auxiliam na quebra de fosfatos de baixa solubilidade (NOVAIS; SMYTH; NUNES, 2007). 
Em relação ao potencial hidrogeniônico $(\mathrm{pH})$ do solo, houve pequeno decréscimo nos valores quando aplicado o SFS $(5,3)$ em relação à testemunha $(5,4)$ (Tabela 4$)$. Isso provavelmente se deve ao fertilizante nitrogenado utilizado (Ureia), em que o $\mathrm{NH}_{4}{ }^{+}$reage com o solo, liberando $\mathrm{H}^{+}$, promovendo acidificação (LOPES et al., 1990). Segundo Malavolta (1981), o superfosfato simples e o triplo não afetam a acidez do solo, mas poderão aumentá-la quando possuírem acidez livre e uma tonelada de fosfato natural, que tem baixa reatividade como a FOC tem uma alcalinidade equivalente a $100 \mathrm{~kg} \mathrm{de} \mathrm{CaCO}_{3}$.

A composição mineral da farinha de ossos calcinada é basicamente apatita $\left(\mathrm{Ca}_{5}\left(\mathrm{PO}_{4}\right)_{3}(\mathrm{Cl}, \mathrm{F}\right.$, $\mathrm{OH})$ ), sendo que o mecanismo de neutralização da acidez do solo baseia-se na reação da hidroxila $\left(\mathrm{OH}^{-}\right)$com o $\left(\mathrm{H}^{+}\right)$da solução do solo (LOPES; SILVA; GUILHERME, 1990). A presença de óxido de cálcio $(\mathrm{CaO})$ verificada em análise $(43,76 \%)$ em sua composição explica os aumentos nos valores de pH em função de sua reação alcalina.

Tabela 4. Potencial hidrogeniônico $(\mathrm{pH})$ em solo com $B$. ruziziensis em função de fontes de $\mathrm{P}$ e tratamentos ácidos avaliados aos 120 dias após transplantio

\begin{tabular}{|c|c|}
\hline Tratamentos $^{1}$ & $\mathrm{pH}$ em $\mathrm{H}_{2} \mathrm{O}$ \\
\hline 1. SFS & $5,3 e^{2}$ \\
\hline 2. Oxá ${ }_{10 \%}$ & $6,3 \quad a b$ \\
\hline 3. Acé ${ }_{10 \%}$ & $6,5 \quad a$ \\
\hline 4. $\mathrm{HCl}_{1 \%}$ & $6,6 \quad a$ \\
\hline 5. $\mathrm{HCl}_{0,5 \%}$ & 6,0 bc \\
\hline 6. FOC & $5,7 \mathrm{~cd}$ \\
\hline 7. TEST. & 5,4 de \\
\hline CV (\%) & 2.25 \\
\hline $\mathrm{F}$ & 47.2 \\
\hline$p$ & $<.0001$ \\
\hline
\end{tabular}

1 Tratamentos aplicados: Superfosfato Simples (SFS); FOC + Ácido oxálico a 10\% (Oxá ${ }_{10 \%}$ ); FOC + Ácido Acético a $10 \%$ (Acé $\left.{ }_{10 \%}\right) ; \mathrm{FOC}+$ Ácido Clorídrico a ${ }_{1 \%}\left(\mathrm{HCl}_{1 \%}\right) ; \mathrm{FOC}+$ Ácido Clorídrico a ${ }_{0.5 \%}{ }_{10 \%}\left(\mathrm{HCl}{ }_{0,5 \%}\right) ;$ Farinha de ossos calcinada (FOC) e Testemunha (Test.). ${ }^{2}$ As médias seguidas pela mesma letra na coluna nẵo diferem entre si pelo Teste de Tukey ao nível de $5 \%$ de probabilidade.

Fonte: Elaborada pelos autores (2018).

Os ossos são constituídos principalmente por hidroxiapatita, que com o processo de calcinação se decompõe em Beta-fosfato tricálcico, óxido de cálcio e água. Segundo Miyahara, Gouvea e Toffoli (2007), a reação a $775^{\circ} \mathrm{C}$ pode ser representada por:

$$
\mathrm{Ca}_{10}\left(\mathrm{PO}_{4}\right)_{6}(\mathrm{OH})_{2} \quad 3 \mathrm{Ca}_{3}\left(\mathrm{PO}_{4}\right)_{2}+\mathrm{CaO}+\mathrm{H}_{2} \mathrm{O}
$$

Uma vez aplicado ao solo, o óxido de cálcio como também o de magnésio promovem a seguinte reação (ALCARDE, 2005) (Tabela 4):

$$
\mathrm{CaO}, \mathrm{MgO}+\mathrm{H}_{2} \mathrm{O}_{\text {(solo) }} \quad \mathrm{Ca}(\mathrm{OH})_{2}+\mathrm{Mg}(\mathrm{OH})_{2} \quad \mathrm{Ca}^{+2}+\mathrm{MgO}^{+2}+4 \mathrm{OH}^{-}
$$

Com o tratamento ácido aplicado, têm-se diferentes níveis de liberação de óxido de Cálcio $(\mathrm{CaO})$ presente na FOC para o solo, que apresenta, consequentemente, valores de pH correlacionados a essa liberação, como pode ser observado principalmente nos tratamentos $\mathrm{HCl}_{1 \%}(6,6)$ e Acé $10 \%(6,5)$, que apresentaram os melhores índices de pH em detrimento da utilização de ácidos. Os outros ácidos testados necessitam de mais concentração para ter o mesmo efeito dos mencionados

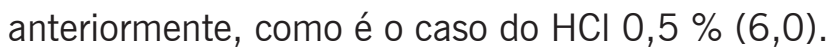


A FOC, mesmo apresentando baixa solubilidade, pode promover ligeira elevação do pH (Tabela 4), porém sem significância. Outro aspecto que também pode ser considerado como um ponto positivo para sua utilização é o poder residual, considerado em outros fosfatos naturais e de liberação lenta e pouco vista em fertilizantes fosfatados mais solúveis, como o superfosfato simples. Este poder residual pode continuar neutralizando íons $\mathrm{H}+$ ao longo do tempo, assim como imediatamente, tendo em vista suas concentrações de $\mathrm{CaO}$.

\title{
Conclusões
}

A acidificação da farinha de ossos calcinada aumentou significativamente a produção de matéria fresca e seca da parte aérea da $B$. ruziziensis quando se utilizou o $\mathrm{HCl}_{1 \%}$ e o Acé ${ }_{10 \%}$ como extratores de fósforo. A utilização da FOC sem acidificação não promoveu efeitos significativos para essas variáveis em relação à testemunha. Houve elevação significativa do pH do solo com a utilização de todos os extratores quando comparados com a testemunha.

\section{Production of Brachiaria ruziziensis biomass fertilized with calcinated bone meal under acid treatments}

\begin{abstract}
With phosphorus reserves declining gradually, the interest in developing alternatives to supply the demand for fertilizers in agriculture has been increasing daily. Thus, organic residues from the slaughter of animals such as bovine bones, which are sources of phosphorus $(P)$ and calcium $(\mathrm{Ca})$, can be used for agriculture. The only impasse in its use is its low solubility and availability of plant nutrients. The objective of this study was to evaluate the productive effects of forage Brachiaria ruziziensis when submitted to fertilization with Calcinated Bone Meal (CBM) under acid treatments (10\% oxalic, $10 \%$ acetic and $1 \%$ hydrochloric acid, respectively). In the evaluations, the following variables were considered: fresh matter of the aerial part (MFPA) and dry matter of the aerial part (MSPA) and hydrogenation potential $(\mathrm{pH})$. As standard, single superphosphate (SFS) was used for comparison. FOC acidification provided significant gains of MFPA and MSPA in the presence of $1 \%$ $\mathrm{HCl}$ and Ace $10 \%$ as extractors of $\mathrm{P}$ over control and $\mathrm{FOC}$ without the use of acids. The use of all acids in FOC provided significant increases in soil $\mathrm{pH}$.
\end{abstract}

Keywords: Phosphorus. Alternative sources. Livestock waste. Forage

\section{Referências}

ALCARDE, J. C. Corretivos da acidez dos solos: características e interpretação técnica. São Paulo: Associação Nacional para difusão de adubos, p. 3-4, 2005. Disponível em: <http://www.anda.org. br/multimidia/boletim_01.pdf>. Acesso em: 23 ago. 2016.

COELHO, A. M.; KARAM, D.; WAQUIL, J. M.; CASELA, C. R.; RIBAS, P. M. Seja o doutor do seu sorgo. Arquivo do agrônomo, Piracicaba, n. 14, p. 8-9, 2002. Disponível em: <http://brasil.ipni.net/ ipniweb/region/brasil.nsf/0/A0432ED449E71B6883257AA0003C3BCA/\$FILE/Sorgo.pdf>. Acesso em: 23 ago. 2016. 
COSTA, M. S. S.; COSTA, L. A.; DECARL, L. D.; PELÁ, A.; SILVA. C. J.; MATTER, U. F.; OLIBONE, D. Compostagem de resíduos sólidos de frigorífico. Revista Brasileira de Engenharia Agrícola e Ambiental, Campina Grande, v. 13, n. 1, p. 100-107, jan. 2009. Disponível em: < http://www.scielo. br/pdf/rbeaa/v13n1/v13n01a15.pdf>. Acesso em: 23 ago. 2016.

COSTA, N. L.; MAGALHÃES, J. A.; TOWNSEND, C. R.; PEREIRA, R. G. A.; PAULINO, V. T. Sistemas Silvipastoris. In: COSTA, N. L (ed.). Formação, manejo e recuperação de pastagens em Rondônia. Porto Velho: Embrapa Rondônia, 2004, p. 212-224. Disponível em: <https://ainfo.cnptia.embrapa. br/digital/bitstream/item/54455/1/livro-pastagens.pdf>. Acesso em: 23 ago. 2016.

DIAS-FILHO, M. B. Degradação de pastagens: processos, causas e estratégias de recuperação. 4. ed. Belém: Empresa Brasileira de Pesquisa Agropecuária (EMBRAPA), 2011, p. 200-210.

DIAS-FILHO, M. B. Pastagens cultivadas na Amazônia oriental brasileira: processos e causas de degradação e estratégias de recuperação. In: DIAS, L. E.; MELLO, J. W. V. (eds.). Recuperação de áreas degradadas. Viçosa: UFV-DPS/Sociedade Brasileira de Recuperação de Áreas Degradadas, 1998. p. 136.

DIAS-FILHO, M. B. Recuperação de pastagens degradadas na Amazônia: desafios, oportunidades e perspectivas. In: SAMBUICHI, R. H. R.; SILVA, A. P. M. da; OLIVEIRA, M. A. C. de; SAVIAN, M. (Org.). Políticas agroambientais e sustentabilidade: desafios, oportunidades e lições aprendidas. Brasília, DF: Ipea, 2014. p. 149-169.

EMPRESA BRASILEIRA DE PESQUISA AGROPECUÁRIA (EMBRAPA). Manual de métodos de análise do solo. Brasília: Empresa Brasileira de Pesquisa Agropecuária (EMBRAPA), 1997, p. 102-105. Disponível em: <https://www.agencia.cnptia.embrapa.br/Repositorio/Manual+de+Metodos_000fzvhotqk02wx5ok0q43aOram31wtr.pdf>. Acesso em: 23 ago. 2016.

EMPRESA BRASILEIRA DE PESQUISA AGROPECUÁRIA (EMBRAPA). Sistema brasileiro de classificação de solo. 2. ed. Rio de Janeiro: Empresa Brasileira de Pesquisa Agropecuária (EMBRAPA), 2006, p. 72-76. Disponível em: <https://www.agrolink.com.br/downloads/sistemabrasileirode-classificacaodossolos2006.pdf>. Acesso em: 23 ago. 2016.

FAGERIA, N. K. The use of nutrients in crop plants. New York: CRC Press, 2008, p. 91-123.

FOOD AND AGRICULTURE ORGANIZATION (FAO). The state of food and agriculture. Rome: FAO, 2009. Disponível em: <http://bit. Iy/dcsAFD>. Acesso em: 23 ago. 2016.

FERRAZ, J. B. S.; FELÍCIO, P. E. D. Production systems - an example from Brazil. Meat Science, v. 84, n. 2, p. 238-242. 2010. Disponível em: <http://www.usp.br/gmab/publica/msjbsf2010.pdf>. Acesso em: 23 ago. 2016.

FERREIRA, E.; BALBINO, T. Carta de cores para a avaliação qualitativa da farinha de ossos calcinada. Diretoria de Patentes: Instituto Nacional de Propriedade Industrial. Protocolo: BR2020140083923. 2014.

FERRO, L. A. B.; CUNHA, J. B.; FERREIRA, E. Farinha de ossos calcinada no desempenho agronômico de estilosantes Campo Grande. In: CONGRESSO INTERNACIONAL DO LEITE; XII WORKSHOP DE POLÍTICAS PÚBLICAS; XIII SIMPÓSIO DE SUSTENTABILIDADE DA ATIVIDADE LEITEIRA. 2013. Anais... Porto Velho: Empresa Brasileira de Pesquisa Agropecuária (Embrapa), 2013. 
INSTITUTO BRASILEIRO DE GEOGRAFIA E ESTATÍSTICA (IBGE). Estatística da produção pecuária: indicadores IBGE. Brasília: IBGE, 2015. Disponível em: < http://www1.ibge.gov.br/home/estatistica/ indicadores/agropecuaria/producaoagropecuaria/abate-leite-couro-ovos_201502comentarios.pdf $>$. Acesso em: 23 ago. 2016.

INSTITUTO BRASILEIRO DE GEOGRAFIA E ESTATÍSTICA (IBGE). Pesquisa da pecuária municipal. Rio de Janeiro: IBGE, 2010. Disponível em: <http://bit.ly/ldMrHi />. Acesso em: 11 mar. 2017.

KOZEN, E. A.; ALVARENGA, R. C. Fertilidade dos solos: adubação orgânica. Cultivo do milho. Sete Lagoas: EMBRAPA Milho e Sorgo, 2010, 6p. (Sistema de Produção, n. 1). Disponível em: <http:// www.cnpms.embrapa.br/publicacoes/milho_6_ed/ferorganica.htm>. Acesso em: 23 ago. 2016.

LAPIDO-LOUREIRO, F. E. V.; MELAMED, R.; FIGUEIREDO NETO, J. Capítulo 08- O fósforo na agroindústria brasileira. In: LAPIDO-LOUREIRO, F. E. V.; MELAMED, R.; FIGUEIREDO NETO, J. Fertilizantes: agroindústria e sustentabilidade. Rio de Janeiro: Cetem, 2009, p. 257-305. Disponível em: < http://www.cetem.gov.br/publicacao/livros/Fertilizantes.pdf>. Acesso em: 23 ago. 2016.

LIRA, M. A.; FARIAS, I.; FERNANDES, A. P. M.; SOARES, L. M.; DUBEUX Jr., J. C. B. Estabilidade de resposta do capim-braquiária sob níveis crescentes de nitrogênio e fósforo. Pesquisa Agropecuária Brasileira, Brasília, v. 29, n. 7, p. 1151-1157, jun. 1994. Disponível em: < https://www.embrapa. br/busca-de-publicacoes/-/publicacao/105143/>. Acesso em: 23 ago. 2016.

LOPES, A. S.; SILVA, M. C.; GUILHERME, L. R. G. Acidez do solo e calagem. 3. ed. São Paulo: ANDA, 1990, p. 2-6. (Boletim Técnico, n.1). Disponível em: <https://www.agencia.cnptia.embrapa. br/recursos/Calagem_boletim_tecnicolD80pHHoncbJ.pdf>. Acesso em: 23 ago. 2016.

MALAVOLTA, E. Manual de química agrícola: adubos e adubação. São Paulo: Ceres, 1981, p. 31-96.

GOMES, F. P; MALAVOLTA, E.; ALCARDE, J. C. Adubos e adubações: adubos minerais e orgânicos. São Paulo: Nobel, 2002, p. 75-83.

MIYAHARA, R. Y.; GOUVÊA, D.; TOFFOLI, S. M. Obtenção e caracterização de cinza de ossos bovinos visando à fabricação de porcelanas de ossos - bone china. Cerâmica, São Paulo, v. 53, n. 327, p. 234-239, jul./set. 2007. Disponível em: <http://www.scielo.br/pdf/ce/v53n327/a0453327.pdf>. Acesso em: 23 ago. 2016.

NOVAIS, R. F.; SMYTH, T. J.; NUNES, F. N. Capítulo VII - Fósforo. In: NOVAIS R. F.; ALVAREZ, V. V. H.; BARROS, N. F.; FONTES, R. L.; CANTARUTTI, R. B.; NEVES, J. C. L. Fertilidade do solo. Viçosa: Sociedade Brasileira de Ciência do Solo, 2007, p. 471-550.

OELKERS, E. H.; VALSAMI, J. E. Phosphate mineral reactivity and global sustainability. Elements, Raleigh, v. 4, n. 2, p. 83-87, abr. 2008. Disponível em: <http://elements.geoscienceworld.org/content/4/2/83>. Acesso em: 23 ago. 2016.

OLSEN, S. R.; KHASAWNEH, F. E. Use and limitations of physical-chemical criteria for assessing the status of phosphorus in soils. In: KHASAWNEH, F. E.; SAMPLES, E. C.; KAMPRATH, E. J. The role of phosphorus in agriculture. Madison: American Society of Agronomy, 1980. p. 361-380. 
PEEL, M. C.; FINLAYSON, B. L.; MCMAHON, T. A. Koppen-Geiger, uptade world map of the Köppen-geiger climate classification. Hydrology and Earth System Science, n. 11, p. 1633-1644. 2007. Disponível em: <http://www.hydrol-earth-syst-sci.net/11/1633/2007/>. Acesso em: 23 ago. 2016.

PORTO, E. M. V.; ALVES, D. D.; VITOR, C. M. T.; GOMES, V. M.; SILVA, M. F.; DAVID, A. M. S. S. Rendimento Forrageiro da Brachiaria brizantha cv. Marandu submetida a doses crescentes de fósforo. Scientia Agrária Paranaensis, v. 11, n. 3, p. 25-34, set. 2012. Disponível em: <DOI: 10.18188/1983-1471/sap.v11n3p25-34>. Acesso em: 23 ago. 2016.

SALMAN, A. K. D. Conceito de manejo de pastagem ecológica. Rondônia: Embrapa, 2007, p. 8-14. (Documento, n. 121). Disponível em: <https://www.infoteca.cnptia.embrapa.br/infoteca/bitstream/ doc/709120/1/doc121 pastagemecologica.pdf>. Acesso em: 23 ago. 2016.

SILVA, F. A. S.; AZEVEDO, C. A. V. de. Principal components analysis in the software assistat-statistical assistance. In: World congress on computers in agriculture, 7., 2009. Anais... Reno-Nevada, 2009. Acesso em: 23 ago. 2016.

\section{Histórico editorial:}

Submetido em: 23/08/2016

Aceito em: 13/03/2017

\section{Como citar:}

\section{$\underline{A B N T}$}

DAMACENO, J. B. D.; FERREIRA, E.; OLIVEIRA, D. M. de; GUIMARÃES, R. S.; GAMA, R. T. da; PADILHA, F. J. Produção de biomassa de Brachiaria ruziziensis adubada com farinha de ossos calcinada sob tratamentos ácidos. Revista Agrogeoambiental, Pouso Alegre, v. 10, n. 1, p. 83-94, jan./mar.

Doi: http://dx.doi.org/10.18406/2316-1817v10n120181078

APA

DAMACENO, J. B. D., FERREIRA, E., OLIVEIRA, D. M. de, GUIMARÃES, R. S., GAMA, R. T. da \& PADILHA, F. J. (2018). Produção de biomassa de Brachiaria ruziziensis adubada com farinha de ossos calcinada sob tratamentos ácidos. Revista Agrogeoambiental, 10 (1), 83-94.

Doi: http://dx.doi.org/10.18406/2316-1817v10n120181078

ISO

DAMACENO, J. B. D.; FERREIRA, E.; OLIVEIRA, D. M. de; GUIMARÃES, R. S.; GAMA, R. T. da e PADILHA, F. J. Produção de biomassa de Brachiaria ruziziensis adubada com farinha de ossos calcinada sob tratamentos ácidos. Revista Agrogeoambiental, 2018, vol. 10, n. 1, pp. 83-94. Eissn 2316-1817.

Doi: http://dx.doi.org/10.18406/2316-1817v10n120181078

\section{VANCOUVER}

Damaceno JBD, Ferreira E, Oliveira DM de, Guimarães RS, Gama RT da, Padilha FJ. Produção de biomassa de Brachiaria ruziziensis adubada com farinha de ossos calcinada sob tratamentos ácidos. Rev agrogeoambiental. 2018 jan/mar; 10(1): 83-94. Doi: http://dx.doi.org/10.18406/2316-1817v10n120181078 